Int. J. Morphol.,

33(2):471-475, 2015.

\title{
Morphology and Location of Surface Landmarks of Foramen Ovale in Kenyans
}

\author{
Morfología y Ubicación de Puntos Anatómicos de Superficie del Foramen Oval en Kenianos
}

\author{
Daniel Kanyata"; Paul Odula**; Lily A. Nyamai*** \& Paul K. Nduati****
}

\begin{abstract}
KANYATA, D.; ODULA, P.; NYAMAI, L. A. \& NDUATI, P. K. Morphology and location of surface landmarks of foramen ovale in Kenyans. Int. J. Morphol., 33(2):471-475, 2015.

SUMMARY: Foramen ovale is a surgically important aperture of the skull since it allows approach to and manipulation of the trigeminal ganglion as it lies in the Meckel's cave. This transfacial approach, Hartel's approach, requires two anatomical points for accurate cannulation; the zygomatic point and the pupil point. This study describes the morphology and location of foramen ovale and describes the pupil point in relation to the medial canthus in the Kenyan population. Department of Human Anatomy departmental review board approved the study. Two hundred dry skulls from the Department of Human Anatomy were studied using a digital calliper with help of a measuring frame. The results were analysed using SPSS version 20. The results showed the length and width of right foramen ovale was $7.69 \mathrm{~mm}$ mean $(\mathrm{SD} \pm 1.31)$ and $4.24 \mathrm{~mm}( \pm 0.64)$ respectively while the left foramen ovale was $7.68 \mathrm{~mm}( \pm 1.23)$ and $4.28 \mathrm{~mm}( \pm 0.74)$. The distance of the zygomatic point from the external auditory meatus on the right was $23.54 \mathrm{~mm}( \pm 2.26)$ and the left was $23.49 \mathrm{~mm}( \pm 2.16)$. The median distances of the pupil point in relation to the medial canthus was $9.5 \mathrm{~mm}$ on the right and $8.1 \mathrm{~mm}$ on the left. These results were significantly different from other population data. Neuronavigational aids to foramen ovale in Kenyans should take this into consideration.
\end{abstract}

KEY WORDS: Foramen ovale; Hartel's procedure; Transfacial; Kenyans.

\section{INTRODUCTION}

The sphenoid bone is a bat shaped bone found on the base of the skull and consists of a body, greater wing and a lesser wing. The foramen ovale is found on the infratemporal surface of the greater wing of the sphenoid bone. The contents of foramen ovale, mandibular nerve and accessory meningeal artery open into the infratemporal fossa (Joo et al., 2013).

Foramen Ovale is found alongside the foramen spinosum and the foramen petrosum. When present the foramen petrosum transmits the lesser petrosal nerve. When not present the nerve exits via foramen ovale (Feneis \& Dauber, 2000).

The foramen ovale is a surgically important aperture in that it lies just distal to the gasserian (Meckel's) cave which houses the trigeminal ganglion. In surgical procedures the foramen ovale is therefore used to access the trigeminal ganglion.
The trigeminal ganglion is the sensory ganglion of the face. Its most important clinical application is that it is affected in trigeminal neuralgia. Although local data is lacking on the prevalence on trigeminal neuralgia, three large and long term epidemiology studies estimate the prevalence of to be 5-8/100,000 (Hall et al., 2006; Katusic et al., 1990; MacDonald et al., 2000).

Trigeminal neuralgia has been described as one of the most painful experiences scoring a mean of $94.32 \pm 10.85$ with the median as 100 out of 100 on the Visual Analogue Scale. The pain usually presents in one or two of the trigeminal distributions namely, ophthalmic, maxillary or mandibular. The presentation of trigeminal neuralgia can be to an ophthalmologist, Ear Nose Throat surgeon, maxillofacial surgeon, Dentist, Neurologist or a primary care physician. Patients who fail to respond to medical treatment of trigeminal neuralgia are often referred to the surgeon for surgical manipulation (Teixeira et al., 2006).

* Department of Surgery, University of Nairobi, Nairobi, Kenya.

** Department of Human Anatomy, University of Nairobi, Nairobi, Kenya.

*** Department of Ophthalmology, University of Nairobi, Nairobi, Kenya.

**** Naivasha District Hospital, Ministry of Health, Naivasha, Kenya. 
Hartel's procedure is a transfacial technique which surgeons use to access the trigeminal ganglion through foramen ovale.

Originally conceived as a free hand technique, it has been improved by using fluoroscopy and Computer Tomography (CT) scan guidance. The placement of the cannula remains a free hand technique. CT scan and Fluoroscopy are used to confirm placement of cannula in the foramen before advancement. Thus the technique remains relevant. The freehand technique is more important in third world settings where imaging services are scarce.

Successful use of the free hand procedure is dependent on the identification of three surface landmarks; the zygomatic point, cheek point and pupil point as illustrated in Figure 1.

The cheek point is $3 \mathrm{~cm}$ lateral to the labial commissure. The zygomatic point is $3 \mathrm{~cm}$ anterior to the external auditory meatus. The pupil point is medial to the pupil when it is directed forwards.

The four points described form an inverted pyramid. The pyramid has the cheek point as the apex, with the other three point's i.e. zygomatic point, pupil point and the foramen ovale forming the base. The base lies on the orbitomeatal plane.

In other studies the pupil point is described subjectively as medial to the medial limbus of the pupil when the eye is facing forward. In this study the medial canthus is used as an objective point to reference the pupil point.

Hartel's procedure which utilizes the three surface points was described using Caucasian skulls. The primary objective of this study is to document the corresponding measurements in Kenyan skulls.

\section{MATERIAL AND METHOD}

The Department of Human Anatomy and Department of Osteology provided access to more than 200 adult human skulls of which 199 were used for this study. Damaged skulls and those with unfused fontanelles were excluded. Surface measurements for each skull were made using a digital calliper and a measuring frame as shown in Figure 2.

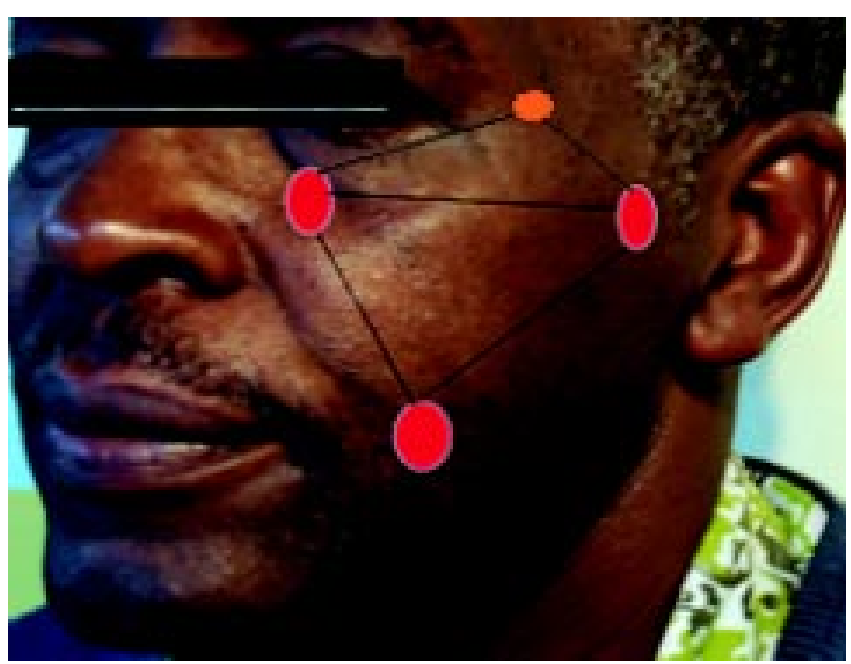

Fig. 1. Cheek point, zygomatic point and pupil point shown in red. Foramen ovale shown in orange. (though shown on the surface in figure 1 , foramen ovale is found deep in the skull base).

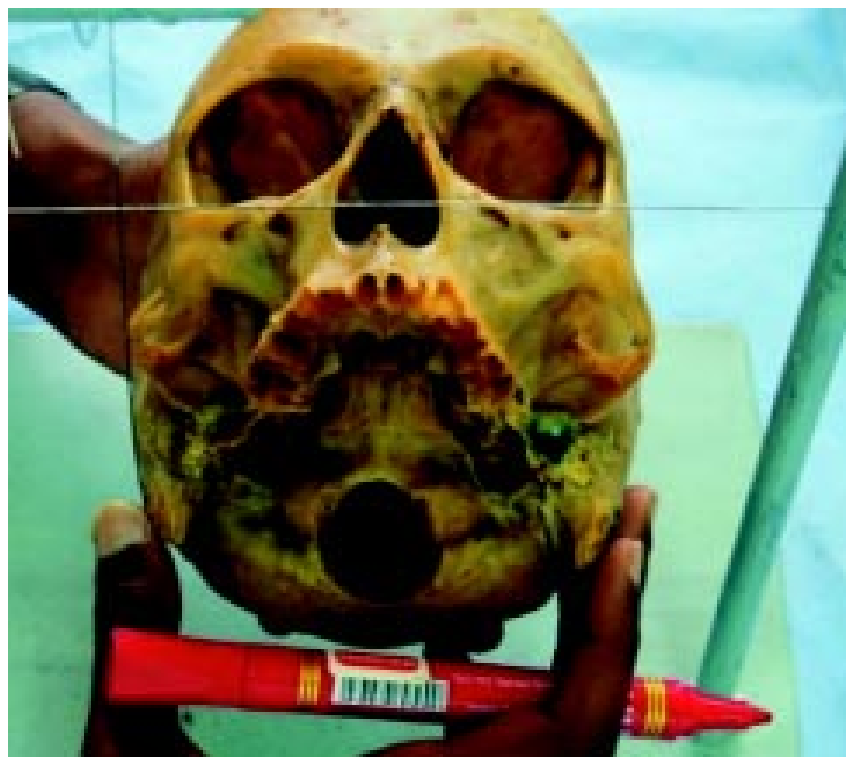

Fig. 2. Measuring frame.

The first measurements made were the length and width of foramen ovale on the right and left side of the skulls. These were the diameters of the widest and narrowest points of the foramina.

The second measurement was identification of the zygomatic points. To locate these points, a virtual straight line is drawn through the centers of the right and left foramen ovale and their exits on the zygomatic bone are the zygomatic points) (Fig. 3). The distance from the zygomatic point to the external acoustic meatus, an easily palpable point in the human being, was measured.

The presence of spurs invading the foramen ovale space was also noted during examination of the skull. 


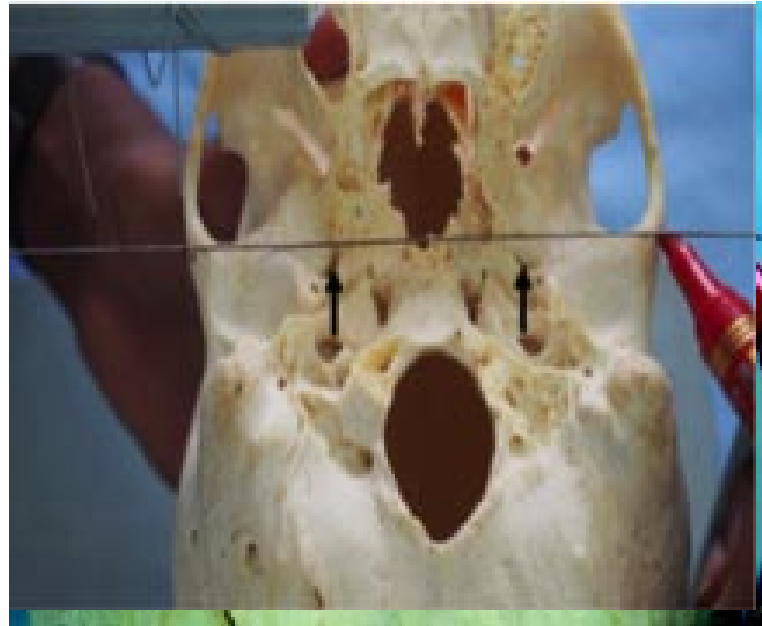

Fig. 3. Line crossing both foramen ovales (arrows) exiting the zygomatic bone, zygomatic point, marked as a red dot.

\section{RESULTS}

The data collected was analysed using SPSS version 20. The results are summarized in Table I below. The length and width was $23.54 \mathrm{~mm}( \pm 2.26)$ and the left was $23.49 \mathrm{~mm}$ ( \pm 2.16$)$ (Fig. 4).

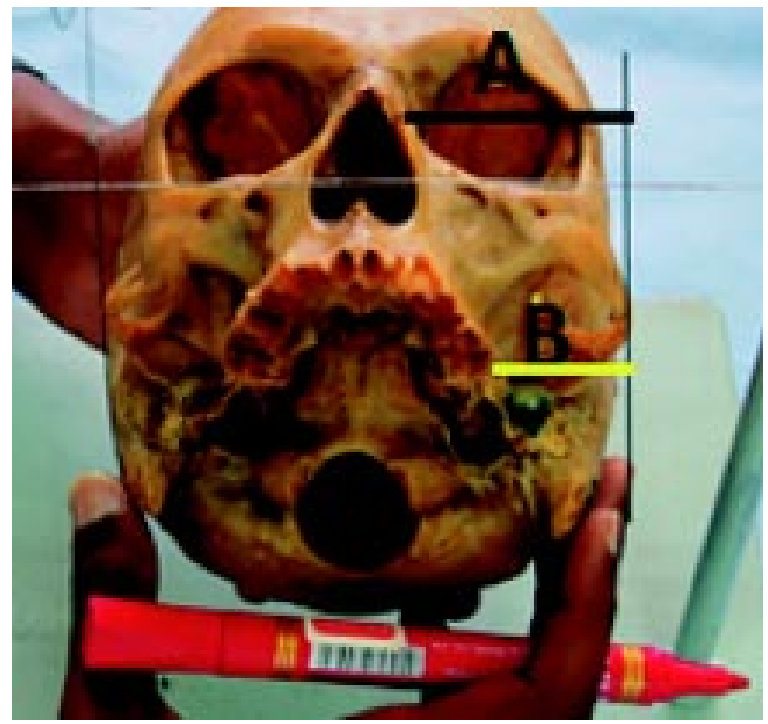

Fig. 4. Difference between Line A and Line B giving the pupil point based on the medial canthus.
The median distances of the pupil point in relation to the medial canthus was $9.5 \mathrm{~mm}$ on the right and $8.1 \mathrm{~mm}$ on the left (Fig. 4).

\section{DISCUSSION}

In our study we found the right foramen ovale was length $7.69 \mathrm{~mm}( \pm 1.31)$ and its width was $4.24 \mathrm{~mm}( \pm 0.64)$ the left foramen ovale was length $7.68 \mathrm{~mm}( \pm 1.23)$ and the width $4.28 \mathrm{~mm}$ $( \pm 0.74)$.

A comparison our results against population data provided by Hwang et al. (2005), Onswuke et al. (2010), Ambica et al. (2012) and Peris-Celda et al. (2013) showed that our measurements are significantly different from other populations. The results of these studies are summarized in Table II below.

Compared to other population data, it can be seen that Kenyans in particular have larger foramen ovales than other populations studied except the Korean populations. If this contributes to lower rates of trigeminal neuralgia amongst Kenyans requires further investigation to find out the prevalence of the condition in the Kenyan setup.

Spurs on foramen ovale represent ossification of pterygospinous and pterygoalar ligaments. However this study did not attempt to differentiate between the two. Our study compares well with Shaw (1993) who found it occurred in $16.1 \%$ of the skulls and $6.8 \%$ were bilateral.

Interest in the size of foramen ovale and the presence of spurs has been correlated with clinical data on patients suffering from trigeminal neuralgia.

This has been to find out which side is affected more and perhaps correlate that with anatomical data, on the size of foramen ovale and on ligaments civinini and hyrtle, gleaned from cadaveric studies (Piagkou et al., 2011).

However in our study the differences in size and morphology between the left and right sides are not statistically significant pointing to a multifactorial cause of trigeminal neuralgia (Bowsher, 1997).

Table I. Results of morphometry of foramen ovale.

\begin{tabular}{llcc}
\hline & & Right & Left \\
\hline Foramen Ovale & Length (mean) & $7.70 \pm 1.31 \mathrm{~mm}$ & $7.68 \pm 1.24 \mathrm{~mm}$ \\
& Width (mean) & $4.24 \pm 0.64 \mathrm{~mm}$ & $4.28 \pm 0.74 \mathrm{~mm}$ \\
Spurs & & $35(17.5 \%)$ & $41(20.6 \%)$ \\
Zygomatic point & & $23.54 \pm 2.26 \mathrm{~mm}$ & $23.49 \pm 2.16 \mathrm{~mm}$ \\
PupilPoint (from medial canthus) & & $9.5 \mathrm{~mm}$ (Median) & $8.1 \mathrm{~mm}$ (Median) \\
\hline
\end{tabular}


Table II. Comparison of Kenyan population data with other population data. P values shown are of the value closest to the Kenyan population data.

\begin{tabular}{|c|c|c|c|c|c|}
\hline \multirow{2}{*}{ Study } & \multicolumn{2}{|c|}{ Length } & \multicolumn{2}{|c|}{ Width } & \multirow[b]{2}{*}{$P$ values } \\
\hline & Right & Left & Right & Left & \\
\hline Osunwoke et al. (2010) & $7.01 \pm 0.10$ & $6.89 \pm 0.09$ & $3.37 \pm 0.07$ & $3.33 \pm 0.07$ & 0.000 \\
\hline Hwang et al.(2005) & \multicolumn{2}{|c|}{$8.18 \pm 0.82$} & \multicolumn{2}{|c|}{$4.06 \pm 0.86$} & 0.002 \\
\hline Peris-Celda et al. (2013) & \multicolumn{2}{|c|}{$6.81 \pm 1.12$} & \multicolumn{2}{|c|}{$3.65 \pm 0.73$} & 0.000 \\
\hline Ambica et al. (2012) & 6.5 & 6.8 & 3.7 & 4 & 0.000 \\
\hline Present study (2015) & $7.70 \pm 1.31$ & $7.68 \pm 1.24$ & $4.24 \pm 0.64$ & $4.28 \pm 0.74$ & \\
\hline
\end{tabular}

Access to the foramen ovale through Hartel's procedure (transfacial techniques) requires anatomical knowledge of three surface landmarks, zygomatic point, pupil point and cheek point. Using skulls we were only able to estimate zygomatic point and pupil point as cheek point would require cadavers.

The zygomatic point in Kenyans lies $2.3 \mathrm{~cm}$ anterior to the tragus. This is lower than $2.5-3 \mathrm{~cm}$ that is described in other populations (Tator \& Rowed, 1976; Son et al., 2011).

The pupil point in our study was also shown objectively to be $0.9 \mathrm{~cm}$ from the medial canthus of the eye on the right and $0.8 \mathrm{~cm}$ on the left. These measurements are not reported in other studies. This is a more objective surface landmark of the foramen ovale compared to the other more subjective description medial to the medial limbus of the pupil. Whether this leads to more accurate cannulation of the foramen ovale requires further study.
The morphology and surface landmarks of foramen Ovale in Kenyans differ significantly from other population findings. Neuronavigational stereotactic cages which may find use in resource poor setups where fluoroscopy is not available therefore would require a redesign. This would make them match the unique morphology and surface landmarks of foramen ovale in Kenyans.

\section{ACKNOWLEDGEMENTS}

I would like to thank the donors of the cavaderic skulls used in the study. I would also like to appreciate Martin Inyimili and Joseph Mwangi for their technical support. Special thanks to the National Museums of Kenya for giving us access to their facilities.

KANYATA, D.; ODULA, P.; NYAMAI, L. A. \& NDUATI, P. K. Morfología y ubicación de puntos anatómicos de superficie del foramen oval en Kenianos. Int. J. Morphol., 33(2):471-475, 2015.

RESUMEN: El foramen oval es una abertura quirúrgicamente importante del cráneo, que permite el enfoque y manipulación del ganglio trigeminal ya que se encuentra en la impresión trigeminal (fosita de Meckel). Este enfoque transfacial, el enfoque de Hartel, requiere dos puntos anatómicos para la canalización precisa; el punto cigomático y el punto de la pupila. Este estudio describe la morfología y la ubicación del foramen oval, y el punto pupilar en relación al canto medial en la población de Kenia. La junta directiva del Departamento deAnatomía Humana aprobó el estudio. Doscientos cráneos secos procedentes del Departamento de Anatomía Humana se estudiaron utilizando un caliper digital con ayuda de un marco de medición. Los resultados fueron analizados mediante el programa SPSS versión 20. Los resultados mostraron que la longitud y ancho del foramen oval derecho fue de 7,69 mm media $( \pm 1,31)$ y 4,24 mm $( \pm 0,64)$, respectivamente, mientras que el foramen oval izquierdoo fue de $7,68 \mathrm{~mm}( \pm 1,23)$ y $4,28 \mathrm{~mm}( \pm 0,74)$. La distancia del punto cigomático desde el meato acústico externo derecho fue $23,54 \mathrm{~mm}( \pm 2,26)$ y el izquierdo de $23,49 \mathrm{~mm}( \pm 2,16)$. Las distancias promedios del punto de la pupila en relación con el canto medial fueron de $9,5 \mathrm{~mm}$ (el derecha) y $8,1 \mathrm{~mm}$ (el izquierdo). Estos resultados fueron significativamente diferentes de otros datos demográficos. El apoyo para la neuronavegación para acceder al foramen oval en kenianos debe tener esto en consideración.

PALABRAS CLAVE: Foramen oval; Procedimiento de Hartel; Transfacial; Kenianos.

\section{REFERENCES}

Ambica, W.; Mamta, S. \& Paramjeet, K. Anatomic variations of foramen ovale. Clinical applications. Int. J. App. Basic Med. Res., 2(3):21-4, 2012.
Bowsher, D. Trigeminal neuralgia: an anatomically oriented review. Clin. Anat., 10(6):409-15, 1997. 
Feneis, H. \& Dauber, W. Pocket Atlas of Human Anatomy. 4th ed. Stuttgart, Thieme, 2000.

Hall, G. C.; Carroll, D.; Parry, D. \& McQuay, H. J. Epidemiology and treatment of neuropathic pain: the UK primary care perspective. Pain, 122(1-2):156-62, 2006.

Hwang, S. H.; Lee, M. K.; Park, J. W.; Lee, J. E.; Cho, C. W. \& Kim, D. J. A Morphometric Analysis of the Foramen Ovale and the Zygomatic Points Determined by a Computed tomography in Patients with Idiopathic Trigeminal Neuralgia. J. Korean Neurosurg. Soc., 38(3):202-5, 2005.

Joo, W.; Funaki, T.; Yoshioka, F. \& Rhoton, A. L. Jr. Microsurgical anatomy of the infratemporal fossa. Clin. Anat., 26(4):45569, 2013

Katusic, S.; Beard, C. M.; Bergstralh, E. \& Kurland, L. T. Incidence and clinical features of trigeminal neuralgia, Rochester, Minnesota, 1945-1984. Ann. Neurol., 27(1):89-95, 1990.

MacDonald, B. K.; Cockerell, O. C.; Sander, J. W. \& Shorvon, S. D. The incidence and lifetime prevalence of neurological disorders in a prospectivecommunity-based study in the UK. Brain, 123(Pt. 4):665-76, 2000.

Osunwoke, E. A.; Mbadugha, C. C.; Orish, C. N.; Oghenemavwe, E. L. \& Ukah, C. J. Study of the foramen ovale and foramen spinosum. J. Appl. Biosci., 26:1631-5, 2010.

Peris-Celda, M.; Graziano, F.; Russo, V.; Mericle, R. A. \& Ulm, A. J. Foramen Ovale puncture, lesioning accuracy, and avoiding complications: microsurgical anatomy study with clinical complications. J. Neurosurg., 119(5):1176-93, 2013.

Piagkou, M.; Demesticha, T.; Skandalakis, P. \& Johnson, E. O. Functional anatomy of the mandibular nerve: consequences of nerve injury and entrapment. Clin. Anat., 24(2):143-50, 2011.

Shaw, J. P. Pterygospinous and pterygoalar foramina: A role in the etiology of trigeminal neuralgia? Clin. Anat., 6(3):173-8, 1993.

Son, B. C.; Kim, H. S.; Kim, I. S.; Yang, S. H. \& Lee, S. W. Percutaneous radiofrequency thermocoagulation under fluoroscopic image-guidance for idiopathic trigeminal neuralgia. J. Korean Neurosurg. Soc., 50(5):446-52, 2011.

Tator, C. H. \& Rowed, D. W. Fluoroscopy of foramen ovale as an aid to thermocoagulation of the Gasserian ganglion; technical note. J. Neurosurg., 44(2):254-7, 1976.

Teixeira, M. J.; Siqueira, S. R. \& Almeida, G. M. Percutaneous radiofrequency rhizotomy and neurovascular decompression of the trigeminal nerve for the treatment of facial pain. Arq. Neuropsiquiatr., 64(4):983-9, 2006.

\section{Correspondence to: \\ Daniel Kanyata \\ Department of Surgery \\ University of Nairobi \\ P.O. Box 00100-30197 \\ Nairobi \\ KENYA}

Tel: +254720837248

Email: danielkanyata@gmail.com

Received: 30-09-2014

Accepted: 23-02-2015 